\title{
CONCEPTUALISING DECADENT TECHNOLOGY: A CASE STUDY OF PATH
} DEPENDENCE IN RADIOTHERAPY

Lisa Wood (2015): Conceptualising Decadent Technology: A Case Study of Path Dependence in Radiotherapy, Science as Culture, DOI: 10.1080/09505431.2015.1065243

To link to this article: http://dx.doi.org/10.1080/09505431.2015.1065243

\section{ABSTRACT}

Large-scale investments in health technologies often have limited evidence for effectiveness when first introduced. Nevertheless, professional and public discourses often present the advantages of such investments, with unknown risks, as necessary and entailing significant improvement. Such discourses are evident with the introduction of the Linac Adapted Conebeam Imager (LACI), introduced to improve the accuracy of radiotherapy treatments. From one perspective, the introduction of such technologies can be considered to be decadent since there is limited, if any, evidence of improvement of current standards and procedures, yet they are promoted as the latest and best technologies for solving societal problems. Connecting the concepts of decadence to those of path dependence, through the case of the LACI, enables the exploration of the 'technical interrelatedness' of technological changes. Building on the concept of path dependence, it is possible to demonstrate how introducing a closely related technology does not only become a low-risk course of action. Rather change is demanded (but not determined) as well as potential alternative systems being obscured. With decadent technologies, any future changes are not only dependent upon past introductions; but also they create a need for future changes. Such a view demonstrates how these technologies may not necessarily offer any improvements, but rather contribute to the creation of ongoing demand for unproven technologies. As a result they may encourage the introduction of increasingly complex technologies.

KEY WORDS: decadent technology, baroque technology, radiotherapy, innovation, path dependence

\section{INTRODUCTION}

Since the development of computed tomography (CT) in the 1970s, there has been an increasing emphasis on visualisation in health care. This visual emphasis has been magnified by increasingly technologised health-care practices as well as hospital fundraising campaigns and widespread media coverage. The justifications for new visualisation technologies, by medical professionals and technology manufacturers alike, are often based on promised benefits, side-lining assessments of actual benefits or risks. Sociological critiques, however, have focused on the normalisation of visualising methods through sociotechnical interactions, controversies over jurisdiction, purpose and utility of the beams and the rise in surveillance medicine (Knight, 1986; Pasveer, 1989; Armstrong, 1995; Burri, 2008). 
It is widely acknowledged within the sociological literature that developments in healthcare technologies are not 'necessarily progressive, not always of value or utility' (Webster, 2007, p. 1). Yet, in some cases, the promised benefits of new technologies, although currently unknown, are presented as obvious. Such 'non-knowledge' results in what Gross (2010) has termed 'ever-new ignorance'. In this paper I examine the introduction of the Linac Adapted Conebeam Imager (LACI) in order to understand how new health-care technologies are framed and represented. ${ }^{1}$ In the mid- to late 2000s LACI was introduced into radiotherapy treatment practice in order to perform Image Guided Radiotherapy (IGRT): a process of utilising CT imaging prior to radiotherapy treatment so as to improve the accuracy of radiotherapy treatment delivery. In 2006, radiotherapy professionals were invited to develop a strategy for the introduction of IGRT (11/09/06, Royal College of Physicians, London). The meeting was organised by a group called Academic Clinical Oncology and Radiobiology Research Network, ACORRN, with a concern about historical introductions of new techniques and equipment into radiotherapy practices without conducting formal clinical studies. Such previous practices were typical in radiotherapy (as discussed by Khoo and Dearnaley (2008)) and their implemen- tation often left vital questions relating to patient safety, accountability and the use of public funds, undiscussed by patient-facing practitioners.

In medical imaging more widely, there are a number of instances where new imaging techniques have been introduced without due consideration of the attend- ant risks. For example, the introduction of CT without an appreciation of the radiation exposure levels involved (Brenner and Hall, 2007; Murphy et al., 2007); the introduction of magnetic resonance imaging in 'serendipitous circumstances' (Joyce, 2008); and the absence of a 'robust means to predict risk' in clinical ultra- sound (Duck, 2005).

In radiotherapy, the introduction of techniques and technologies without clinical testing occurs when:

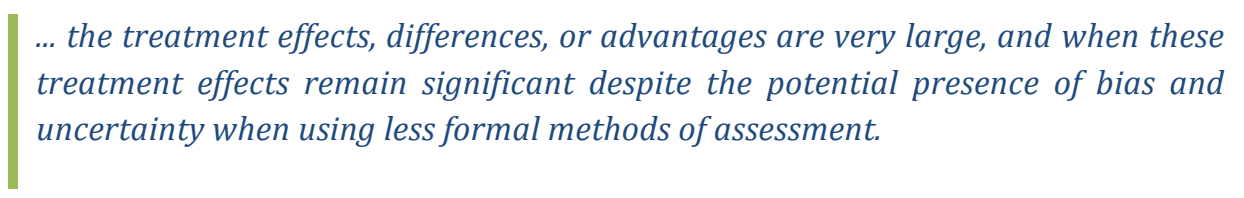

(KHOO AND DEARNALEY, 2008, P. 234)

What is notable about these cases is that it is difficult to see how any associated risks could be identified prior to technologies' widespread use. On this basis and despite the ACORRN meeting, IGRT was well established within UK radio- therapy departments by 2010 even though the first research trial resulting from the ACORRN meeting was only due to start that year (Institute for Cancer Research (ICR), 2010). Furthermore, in a 2008 report of the meeting, the co-chairs stated: 'The consensus was that a new trial [of IGRT] would be unnecessary when new or changed practice is evidently worth implementing' (Price and Heap, 2008, p. 379). 
In advocating the need for a randomised controlled trial for prostate IGRT, Khoo and Dearnaley (both based at the ICR and actively involved in the design of IGRT studies) state that the only method of 'logically confirming' the true value of prostate IGRT is a prospective randomised controlled clinical trial to assess patient outcomes. Elsewhere others have supported this, stating that 'Enthusiasm for a novel technology should be the basis of its scientifically sound, academic evaluation but not the basis for its general introduction into routine clinical practice' (Baumann et al., 2008, p. 1191).

Instead, it is possible to argue that the introduction of IGRT is driven by specific forms of rhetoric rather than evaluation. For example, charity organisations raising funds for the technology and manufacturers often promote IGRT by extolling the benefits of change (Ashmore, 2012). Essentially the effects, differences and advantages of introducing IGRT are represented as significant, with the change in practice 'definitely worth implementing' by those working in the field.

In this paper, I analyse the introduction of an IGRT system - the LACI- and argue that it represents a 'decadent' technology (see Kaldor, 1981). In so doing, I seek to answer the following questions:

. Are the new technologies introduced into clinical settings necessarily better than existing technologies?

. If not, how are they justified?

. And, finally, how might we understand their introduction analytically?

I will answer these questions using the notion of decadent technology drawn from the work of Kaldor (1981). I use this concept to highlight a constellation of issues present in the LACI case study that problematise the notion that change always produces benefits. These issues include: (1) new technologies do not necessarily offer improvements in clinical care; (2) however, they can contribute to ongoing demands for change; and (3) they can create information overload which other (human or non-human) components of the system cannot act upon. In the following section I provide an initial conceptual outline of the relation- ship between decadent technology and the concepts of path dependence and lockin. This is followed by a description of IGRT and Linac Adapted Conebeam Imaging. The empirical section draws upon the case study described above, to illustrate the conceptualisation of decadent technology through an account of the possibilities created, or even demanded.

\section{ANALYTICAL PERSPECTIVES}

The notion of decadent technologies is informed by the work of Kaldor (1981), specifically her ideas surrounding baroque military technologies. In this paper I combine this concept of baroque technology with the concepts of path dependence and lock-in to broaden the conceptualisation of decadent technologies. In the following section I describe each of these in turn. 
KALDOR'S BAROQUE ARSENAL

Described as a theorist of war, Mary Kaldor has studied the political and economic context of war since her first book was published in 1981. In this book, published in the midst of the Cold War, she described the creation of large-scale weapons technology as a contradictory process in which cutting-edge technical developments are embodied in a 'Baroque Arsenal' (Kaldor, 1981, p. 4). The baroque arsenal, Kaldor argues, stems from the proposition that modern military technology is not 'advanced', but rather it is 'decadent' invoking characteristics similar to Baroque art or architecture: for example, extravagance and complexity. Kaldor suggests that purchasing 'bigger and better' technological systems is considered a way of enhancing the power of a nation's armed forces. Therefore, perpetual change in the range of new technologies (or elaborations on existing technologies) enables manufacturers to stay in business through the pursuit of 'trend innovation' (Kaldor, 1981, p. 4) - that is, innovations that remain embedded within established traditions.

Kaldor asserts that through the development of existing systems, these systems become introverted; for example, those involved in design and manufacture concentrate on the goal of perfecting them in order to reach some, as yet unproven, objective. She concludes that baroque military systems, through perfecting them- selves in this way, become increasingly large, costly, elaborate and less and less functional, while maintaining a grandeur and ability to instill social awe that is found in other aspects of the baroque-art, architecture or technology.

Beyond studies of the political economy of war, Kaldor's work is often briefly cited in studies of invention (Hughes, 1987; Murakami Wood, 2009; Stirling, 2009). For example, Hughes (1987), in his conceptualisation of technological styles, used Kaldor's work, albeit fleetingly, to demonstrate how sociologists and historians of technology describe the construction of technological systems. Hughes credits Kaldor with identifying a Baroque style of military technology.

Sociologist Maggie Mort, when looking at the development of the Trident sub- marine and missile network in the UK, also applied the concept suggesting that the development of Baroque technologies is a process:

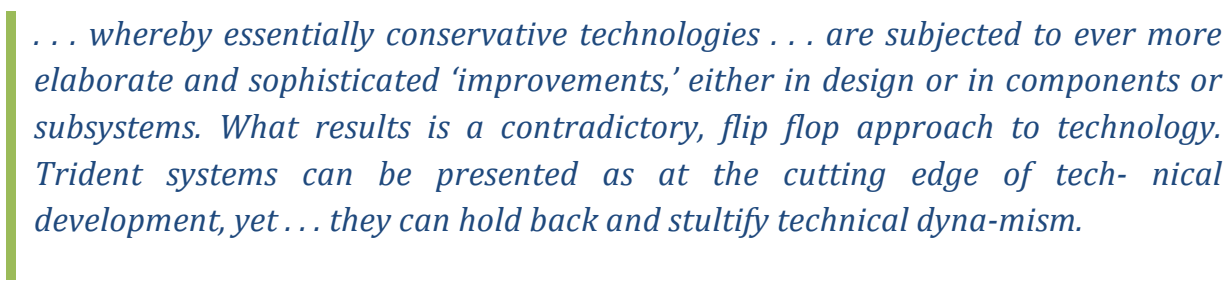

(MORT, 2002, P. 21)

Mort's interpretation of Baroque systems exemplifies the decadence Kaldor dis- cusses: ever more elaborate and contradictory systems illustrative of the Baroque Style. As Kaldor 
suggests, whether systems are 'innovative' in nature involves challenging what constitutes technological advance.

TREND INNOVATION, TECHNOLOGICAL PARADIGMS, PATH DEPENDENCE AND LOCK-IN

Baroque technological systems can be considered the product of path-dependent processes, or what Kaldor termed 'trend innovation', reinforcing particular techno- logical pathways and blocking other possibilities (Barry, 2000). Kaldor (1981) argued that investment in technologies which do not fit in with the trend innovation is not funded or such systems are not developed because funds and expertise are directed away from these other modes of operation. Such trend innovation entails paradigmatic, path-dependent processes, or specific elaborations on existing technologies.

Trend innovation reflects the notion of technological paradigms, described by economist Giovanni Dosi (1982) based on Kuhnian model of scientific paradigms. Technological paradigms, according to Dosi, are 'blind' to other possibilities and encourage the analysis of technological development along a path-dependent route. Within technological paradigms it is assumed that the direction in which technological development will take place is decided long before the 'invention' process. As such, the path taken within the technological paradigm shows a momentum of its own and defines the direction of the problem-solving activity.

The analytical device of path dependence therefore provides a means to analyse the pathways of technological development. The most cited example of such technological development is the emergence of the QWERTY typewriter keyboard, described by David (1985). David, an economist, used the case of QWERTY to develop the notion of path dependence. David draws on Brian Arthur's work to explore the 'technical interrelatedness' of the QWERTY keyboard; for example, the compatibility between hardware and software and, more importantly, the ability of the typists to use a particular keyboard. David posited that through the purchase of QWERTY keyboards employers reinforced that technology's diffusion and therefore the likelihood of typists learning that to use that specific keyboard configuration. As such, it became more economical for non- QWERTY typewriter manufacturers to create a system compatible with the exist- ing QWERTY typists than for the QWERTY typists to learn a new system. David provided examples of an alternative keyboard, the Dvorak Simplified Keyboard, which he characterised as more efficient than the QWERTY one and suggested that industry standardised on the wrong system. In presenting the path-dependent story of the QWERTY keyboard, of how the eventual outcome of the market was shaped by 'temporally remote events' (David, 1985., p. 332), the dynamics of change are shown to be neither completely deterministic nor random (David, 2007).

What this case also reveals is that path dependence can lead to lock-in where possible alternatives are side-lined, for example, by the adoption by workers and employers using 
only one form of system. As Kidder (1982) described in his exploration of the race to create a microcomputer, customers do not, or only rarely, change their manufacturer. Introducing a technology which is closely related to that already in place becomes the 'low-risk course' of action (MacKen- zie and Wajcman, 1999, p. 21). As such, we cannot ignore the possibilities existing technologies create, or even demand, or the potential for lock-in to specific technologies (Dosi, 1997).

Yet path dependence and lock-in are not without their critics. Indeed, as Dosi (1997) has stated, it is hard to see anything other than the path taken when you can only see the one history that occurred. Principally, those criticising path dependence argue that it is a deterministic concept, which explains stability and not change (Kay, 2005). Furthermore, it shows that paths exist rather than why they exist (Stack and Gartland, 2003); deciding that 'history matters' does not provide a clear and convincing way of describing decision-making over time (Kay, 2005). In studying path dependence, there are also methodological problems with identifying where the path starts (Tiberius, 2011) and, similarly, lock-in may be conditioned by the timeframe under scrutiny (Garud et al., 2010). That is to say that lockin may be reversed; it is entirely possible that the paths may not last forever and that technologies may be replaced by other systems in the long run. An example of this is the well-cited argument of lock-in between video home system (VHS) or Betamax video recording equipment (Arthur, 1990), now essentially obscured by the emergence of DVD systems and thus only visible if the timeframe under analysis allows.

Despite the critiques, however, path dependence allows a valuable analytical perspective for analysing ever-increasing investment to adoption and the way in which change occurs. As Kaldor posited, Baroque technologies create demands for change. This assertion is useful in advancing the arguments for path dependence: not only does introducing a closely related technology become a low- risk course of action, not only does it become the only course of action, it is demanded. Alternatives are obscured and any future changes are utterly dependent upon past introductions.

\section{METHODS}

This paper draws on a research project entitled 'The Ray of Hope: Hidden Work and the Pursuit of Accuracy', which is an examination of the introduction of LACI technologies into radiotherapy practice (Wood, 2012). The project involved ethnographic work in two UK Radiotherapy departments in two different National Health Service (NHS) hospitals for several months, and draws on ten years previous experience of training and practising as a therapy radiographer. Through learning how to become a radiographer, I developed a situated awareness of the field; for example, how to behave, to speak, to understand the language and to be understood in using that language. Through my subsequent social science research training I developed a reflective and critical awareness, developing new ways of seeing, building on what is already known or embodied. It is the fusion of these subject positions that enabled me to critically examine the detail of the LACI emplacement. 
The two sites of research, the Gray Cancer Centre (GCC) and the Sieverts Hospital (SH) were of similar size but at different stages of a machine replacement programme. At GCC, new practices had been developed and implemented for over two years. At SH these were in their infancy. Rather than conducting a comparative appraisal about variations in practices, the observations across these two hospitals attended to how LACI was introduced into the clinical setting.

A 12-month period of fieldwork across the 2 sites yielded 322 hours of observations including observations of what was being done by clinical and non-clinical staff working with the system. Observations also took place at a variety of locations and settings to explore the way organisational frames shape, and are shaped by, the technologies they are associated with. The ethnographic approach allowed the assembly of the ethnographic object to be explored, and hence disentangled, in the multi-sitedness and multi-temporality of the field. The data in this paper are taken solely from the SH site.

The research was approved by the NHS Main Research Ethics Committee and at each of the two sites by the local Trust Research and Development committees.

EMPIRICAL ANALYSIS

IMAGE GUIDED RADIOTHERAPY

Radiotherapy, or radiation therapy, is the treatment of cancer using high-energy (megavolt) $\mathrm{X}$-rays. A course of radiotherapy is given over a period of daily treatments, the number of which depends on the tumour site being treated for radical, or curative, treatments; for example, this ranges from 5 to 40 treatments (called 'fractions'). IGRT is used in radiotherapy treatments to improve the accuracy of radiotherapy treatment beam positioning, to ensure the radiation dose is delivered to the correct location each day. In improving the accuracy of radiotherapy treatments, the margins of healthy tissue around the tumour volume can be reduced and, as such, reduce the side effects experienced by the patients. The LACI system is being introduced into radiotherapy practices with the aim of improving IGRT capabilities. This system is rapidly being implemented across the UK and involves the adaptation of a linear accelerator (radiotherapy treatment machine) enabling it to produce CT-like images, also termed LACIs.

LACI, manufactured by Vol-im, is one of two commercially available systems for obtaining cone beam CT (CBCT) scans in radiotherapy. An alternative system, the 3D Scanner (3DS), is produced by the manufacturers Hapian. A CBCT scan, aiming to improve the accuracy of radiotherapy treatments, allows practitioners to verify, in $3 \mathrm{D}$, the position of a patient before the radiation beam is turned on, something which traditional verification systems cannot do. Through reviewing the CBCT scans, comparing CBCT images to an image taken of the patient prior to starting a course of treatment, practitioners are able to reposition patients before each daily treatment to ensure that the treatment is given in the exact location. 
When CBCT imaging is discussed in practice, there is a strong rhetoric of inevitability with proponents espousing a belief in technological change as beneficial. This is reflected in national advisory groups and evaluation projects (Centre for Evidence-based Purchasing (CEP), 2010a, 2010b, 2010c; National Radiotherapy Advisory Group (NRAG), 2007). Despite the uncertainty regarding the long-term consequences of the additional radiation doses involved in CBCT scanning, it is widely acknowledged that there is sparse evidence to support the implementation of these scans into practice. Furthermore, in 2010, a report from the UK's CEP stated that there was little evidence to date on the direct patient benefit of IGRT techniques (CEP, 2010c).

In 2007, one of the co-designers of an IGRT system predicted that radiotherapy treatments will transition to 'complete dependence' upon image-guided tech- niques in the future (Jaffray, 2007, p. 244). Furthermore, in a recent evaluation of CT-based IGRT systems, or tomographic imaging, conviction about potential benefit is further demonstrated. The report states:

... there is, as yet, little clinical evidence to demonstrate its effectiveness [yet] there is no doubt in the clinical and scientific community that it has great potential to improve radiotherapy delivery for a significant proportion of patients treated in the UK.

(CEP, 2010A, P. 3)

This suggests a drive for IGRT that precedes knowledge of its benefits. Ling et al. (2006) state that:

The intense hype [surrounding IGRT], prior to establishment of clinical benefits, has prompted concerns that IGRT circa 2005 is driven in part by technology.

This view of IGRT as driven partly by technology is supported by Howard Amols, the chief of clinical physics at Memorial Sloan Kettering Cancer Centre in New York who described IGRT as an example of 'new technology searching for a problem before the need has been demonstrated' (Amols et al., 2006, p. 3584). The extent to which evidence for clinical benefits, or improved out- comes, of IGRT was developed can be considered disproportionate to the rate at which the systems were adopted. Furthermore, despite Jaffray (2007) anticipating a 'long but exciting road', it is interesting to note that IGRT technologies became well established within radiotherapy departments in the UK during the three years after this prediction.

It is on this basis that I draw parallels between IGRT systems and the baroque arsenal of military technology as discussed by Kaldor (1981). In this vein, considering the increasing cost and declining effectiveness of changes to radiotherapy treatments, it is possible to conceptualise IGRT as a decadent technology—that is an extravagant and overly complex 
system that follows a particular technological trajectory to the exclusion of others. In order to do this, I describe in detail how the LACI system was introduced into a UK hospital in 2008. In thinking through the concepts of path dependence and lock-in, I aim to show how health technology manufacturers promoted forms of technological change that fitted within existing NHS organisational conventions.

HISTORICAL RADIOTHERAPY TREATMENT POSITIONING TECHNOLOGIES

The LACI system, designed to acquire CBCT scans of patients in order to verify the positioning of radiotherapy treatments, was introduced on top of two verification systems already in use; the Electronic Portal Imaging (EPI) system and port films. The EPI system involves a detector panel positioned parallel to the treatment machine 'head'; that is, directly opposite the point from which the high- energy, mega-voltage $(\mathrm{mV}), \mathrm{X}$-ray radiation treatment beam is produced (see Figure 1).

The EPI detector panel captures the $\mathrm{mV}$ (treatment) X-rays once they have passed through the patient and converts them into a digital image which can be reviewed on a computer screen by (suitably trained) practitioners. Due to technical reasons, EPI images lack definition, meaning that the $\mathrm{mV}$ EPIs do not produce an image showing soft tissue structures of patients' internal anatomy. The anatomy displayed on an EPI image, therefore, is mainly bony and now considered, by some, inadequate for effectively checking the positioning of the radiotherapy treatment. 


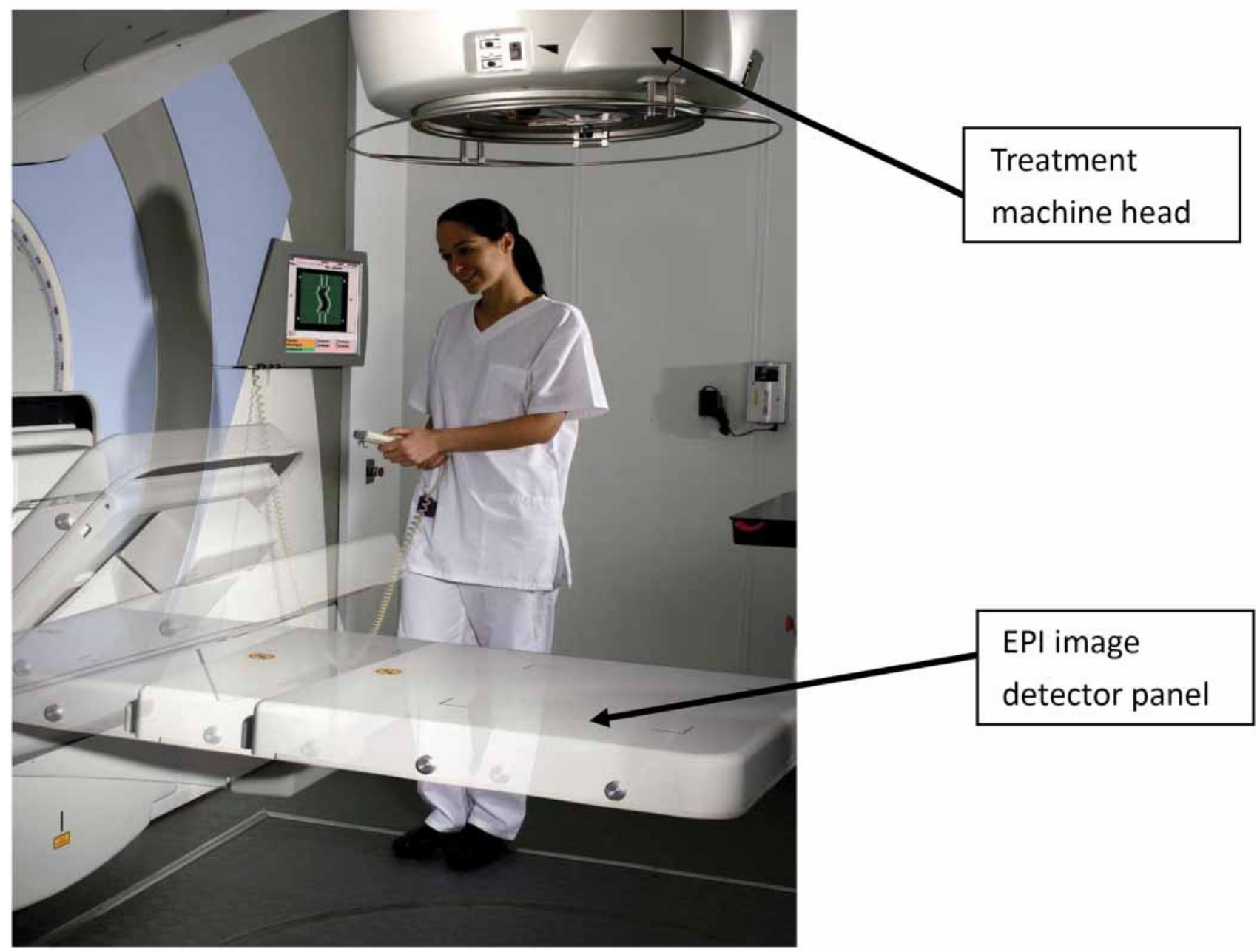

Figure 1. The EPI system uses a flat panel detector housed in identical casing to the LACI detector panel so they look indistinguishable. Source: Elekta.

Development of EPI systems began in the 1950s but they were not introduced into many UK radiotherapy departments until the late 1990s (Antonuk, 2002). Originally featuring a camera coupled to a device which converted X-rays into light, these early EPI systems were replaced with flat panel imagers in the last decade. A flat panel imager uses digital technology in order to create an image from X-rays converted into light. The EPI systems were introduced to replace radiographic film-based systems. These film-based systems, or port films, required practitioners to manually position a cassette containing an X-ray film parallel to the X-ray source and thus opposite to the radiation treatment beam. This was a time-consuming task that sometimes resulted in practitioners positioning the film incorrectly and therefore not acquiring any image or just part of an image. The port film would then need chemical processing in the same way as a diagnostic X-ray film. This process was messy and costly, due to the maintenance of the processing equipment, and the film itself became prohibitively expensive. At the $\mathrm{SH}$, the demise of port film for radiotherapy treatment verification was forced due to the unconnected radiology 
department going 'filmless', making the hospital Trust reluctant to replace existing filmprocessing equipment.

So, existing treatment-imaging devices (EPI, port film and Computed Radiography) have involved the capture of radiation to produce an image of the patient. Current EPI systems even use a flat panel detector housed in identical casing to the LACI detector panel so they look indistinguishable. All these previous systems have been dependent upon the use of Xray imaging. Yet there are other possibilities available for performing IGRT such as ultrasound scanning or the use of optical devices. This draws us back to the point made by Kaldor (1981) that investment is made in trend innovation, which can preclude the search for alternative technological solutions.

THE HISTORY OF LACI

Next, I present a detailed history of IGRT, particularly the LACI introduced at the SH, in order to analyse how a medical technology can be conceptualised as decadent. In particular, the introduction of the Pozo gantry I discuss below illustrates how path dependence shapes the organisation of LACI.

I start with the following story, which is composed of my recollections of the first time the LACI was introduced to me as a clinical radiographer working at the SH (in 2004) and also from field notes during observations at that field site as part of a doctoral study in 2008.

\section{AUTHOR'S NARRATIVE:}

It's summer 2004, we're holding a staff meeting in the radiotherapy department at Sieverts Hospital. We (the therapeutic radiographers present) have just been informed that the new radiotherapy treatment machine, linear accelerator, which will be installed into the department, will have a Pozow platform. I get the impression we are meant to be pleased about this but I'm not sure any of us know what it means. The deputy manager explains that with the Pozow platform, produced by the manufacturers Vol-im, we will be able to get a new piece of technology installed at a later date [the LACI]. The 'platform' is the part of the radiotherapy treatment machine which is installed into the wall of the treatment room. It is onto this that the components of the linear accelerator, those which are seen in the treatment room at least, are attached. Our manager adds that by installing the Pozow platform we will be 'primed for Image Guided Radiotherapy'. The deputy explains that this means we will be able to perform CT scans of patients before they have their treatment. I ask if we will actually use this type of technology. I am reprimanded for my negativity and it is made clear that this is not a topic for discussion. I blush and decide to remain silent. The Pozow platform is installed later that year.

In October 2008, during the fieldwork for my PhD in Science and Technology Studies, I watch an engineer working for the manufacturers of the LACI technology remove a sticker off this same Pozow platform. The sticker branded the linear accelerator: 'Vol-im Pozow platform'. The engineer is able to remove the word 'platform' from the sticker leaving the 
'Vol-im Pozow' part. The linac is no longer primed, as the manager had stated. It has fulfilled its destiny. The holes which had previously been covered by the casings of the old linac are now used to support the Linac Adapted Conebeam Imaging (LACI) attachment ${ }^{2}$; attaching it to the platform which was installed in 2004. I wonder if there was any chance of this machine not being fitted with a LACI attachment. I also wonder whether any holes on Pozow platforms remain unfilled in departments elsewhere.

In 2006, the SH launched a fundraising campaign in order to raise funds for the purchase of the LACI system. When this campaign was launched, alternative systems for conducting IGRT were available. These approaches such as ultra- sound scanning or optical devices were often cheaper and involved lower or no doses of radiation. However, as the story above shows, two years prior to the launch of the fundraising campaign, a Pozo Platform had been installed into the department in question. Already in use as a treatment machine, its introduction represents an example of a trend innovation (Kaldor, 1981); moreover, its introduction makes lock-in to a particular clinical system more likely. Keen to promote their IGRT enabling systems, the manufacturers 'offered' this platform in order to increase the likelihood that the hospital would upgrade to the full LACI system. As a result, possibilities for the introduction of different system were reduced. The introduction of the Pozo platform, an event temporally remote to the purchase of the LACI, can also be considered to influence the introduction of the LACI system four years later. This example illustrates that path dependence and lock-in happen before a technological system is actually introduced; in this sense, the ground is prepared for its introduction.

\section{NOT NECESSARILY AN IMPROVEMENT}

The LACI represents a trend innovation within a technological paradigm due to the mode in which it operates; that is, through radiation exposure. As previously mentioned, verification processes established prior to the introduction of CBCT imaging-for example, the EPI system also utilised radiation exposures to check patient position. Thus the LACI, a system also using radiation and a similar methodology, was not a threat to existing processes. As such, introducing a technology which is closely related to that already in place becomes the 'low- risk course' of action (MacKenzie and Wajcman, 1999, p. 21).

As Kaldor (1981) suggests, whether systems are an improvement involves how improvement is framed. As such it is possible to question whether the LACI was an improvement over the existing EPI practices. For example, the ability to visualise a patient's soft tissue anatomy on a CBCT scan is an improvement on the EPI system, which relies on bony anatomy or radiopaque markers implanted inside the patient. However, the extent to which this is an improvement in radiotherapy treatments for prostate cancer has been debated due to other inaccuracies in the planning process (Moore et al., 2006; McNair et al., 2008).

Kaldor (1981) argued that questions of effectiveness or efficiency are difficult to test for with military technologies, which rely on 'real-world' experimentation. The same could be 
said for clinical systems like the LACI. As highlighted earlier, questions of efficiency and efficacy regarding the LACI system remain unanswered and dependent upon framing. If the aim of LACI is to reduce long- term side effects, then whether this aim is met will not be known for many years to come, after which thousands of patients will have been exposed to this imaging technique. However, the gradual insertion of components to the LACI system into clinical settings-for example, the Pozo platform-ends up side- lining other technologies. This happens not only for technical reasons, but also because the components change everyday practices. On the one hand, EPI and its predecessor, port film, were crucial in locking radiotherapy departments into radiographic modalities of verification; subsequently, the process of adoption tends to improve those technologies that have been adopted (MacKenzie and Wajcman, 1999). On the other hand, as the components of the LACI system are gradually introduced, clinical staff find ways to smooth out glitches and develop work-arounds; these practices mean that the LACI system gained momentum within the departments in which it was located. Whether this represents an improvement on existing systems becomes a moot point.

\section{NEEDLESS COMPLEXITY?}

Whereas the earlier introduction of the Pozo platform helps to explain why the LACI system is adopted, this does not resolve whether the LACI improves existing practices. It may actually do the reverse, and introduce needless complexity. For example, on a visit to the SH three months after practitioners had received training in how to use the system, one radiographer discussed a clinical case with me where CBCT scans being taken were consistently outside of the five millimetre tolerance accepted between the reference or pretreatment image and the LACI image.

In reviewing the scans after the radiotherapy treatment, radiographers learnt that the treatment radiation given to the patient would not cover the required volume of tissue as planned for. As a consequence the radiographers had been taking daily CBCT scans of the patient in order to see if this limited tissue volume coverage was consistent. Due to this continuing discrepancy a decision was made to create a new plan for the patient's treatment that would ensure that the entire target volume was treated. The patient was asked to attend another pre-treatment scan and the planning process was performed once more.

When the patient re-started his treatment, Sarah, a Senior Radiographer involved in this case, told me that the old plan could have been adjusted using the same method that was used with the previous verification system (i.e. EPI). Furthermore, two other radiographers involved in this case, Angela and Nikki, also told me that they believed that the patient's treatment was complicated by the presence of the CBCT. Moreover, they claimed that they had tried to use all the information gained from the scan in order to make a decision, but this had actually hindered the decision-making process. The addition of the CBCT scans in this treatment had complicated, rather than advanced, practice. It demonstrates that the introduction of new technologies does not necessarily improve treatment. Rather, it is 
resonant with Kaldor's (1981) argument about Baroque technologies being simultaneously elaborate yet less and less functional.

This is also evidenced by another patient case. Here the CBCT scans showed the patient to be consistently in a different treatment position to that on the planning scan; a re-plan resulted in an identical treatment plan being produced, thus expos- ing the patient to additional scan appointments and the associated increased radiation dose. These two cases highlighted how, despite the frequent CBCT scans being incomparable to the pre-treatment scan, no treatment plan could be produced that improved upon this 'fit'. It is apparent that the quantity of information obtained from these LACI scans creates a 'visual gluttony', as posited by Haraway (1988) in her discussions of how visualising technologies are 'without apparent limit'. The LACI, in this sense, offers practitioners more information that they are able to work with.

These examples of re-planning, rescanning and remaking treatments contrast with the claims I presented earlier in this paper about the axiomatic effectiveness or patient benefit of IGRT. The examples show how it is not always possible, for example, to match the reference scan to the LACI image; that is, to achieve the aims of the technology. Consequently, the LACI's role in producing images creates situations where its results are difficult to interpret. If the scan shows the radiographer that the patient is not in the correct position, but the radiographers cannot process this information in order to produce an alternative intervention, the production of the scan in the first place comes to represent a form of decadence. An alternative reading might be that it is not the system that is decadent but rather the skills of the radiographers are inadequate to introduce or deal with the system to its full potential. However, this fails to acknowledge that 'the system' is not simply the technical artefacts (i.e. LACI); it is the whole socio-material network, including humans and machines.

ONGOING DEMANDS FOR NOVELTY AND THE RACE TO RELEASE

Vol-im, the manufacturers of the LACI, and Hapian, who make an alternative system called the 3DS, both chose to create a kilo voltage system to 'add-on' to their existing linear accelerators. Patin, the third linac manufacturer, had chosen to develop a high-energy, $\mathrm{mV}$, CT imaging system, the popularity of which, although installed in some UK hospitals, reflects their less competitive position in the whole linac market.

During the training phases of the LACI introduction at the $\mathrm{SH}$, the representative from Volim made frequent references to the race to release the LACI in order to beat Hapian onto the market. He said that this was the reason why certain parts of the machine are not 'interlocked'. These machine parts can be inserted into the LACI radiation source head in order to shape (collimate) and filter (make more homogeneous) the X-ray beam. However, because they are not interlocked there is no mechanism in place to ensure that, prior to a scan being taken, the correct collimator or filter is in place. When a scan is taken the practitioner inputs into the software which collimator and filter are in the machine head. 
This affects the way in which the scan is converted into an image for the practitioner to view. Because of the lack of interlock, there is no communication between the software and the filters and collimators to ensure that those inserted are those selected in the software. An incorrect filter or collimator alters the quality and size of the resultant scan which is not in itself harmful to a patient; however, it can require further scans to be taken, thus resulting in an extra radiation dose for the patient.

The development work regarding the interlocking collimators and filters can be contrasted with the holes in the Pozo Platform. The holes are necessary for the physical positioning of the LACI system, yet the interlocking of the components are safety features, not required by law, which can be worked around or developed once the system is in situ. Interlocking is therefore sidestepped in order to gain competitive position. Furthermore, the manufacturer's trainer for the LACI system also suggested that an outcome of the race to release is the 'much higher' radiation dose delivered by the 3DS system compared to that of the LACI. ${ }^{3}$

The nature of the race thereby shapes the resultant product. The race demands technological change leading to decisions being made regarding features which could be developed for later product releases in order to produce a system that can make it onto the market before the rivals. The race also suggests that there will be options for those involved in the purchase of the technology: a choice between Vol-im and Hapian, LACI and 3DS. However, at the SH the LACI was scripted to be added onto the Pozo Platform. So the race is not necessarily for the purchase of this system. In order to ensure that they do not change systems, customers need to believe that their machine can either be upgraded or replaced with another, similar machine. In these cases then, representations of potentialities shape investment, suggesting that processes of path dependence and lock-in influence expectations about future improvement (i.e. Progress) and not just increasing returns to use (David, 1985).

The LACI system can be considered decadent in the sense that representations of future improvement drove the adoption of more than one system. For example, during the installation phase of the LACI, members of the radiotherapy department staff frequently implied that having one LACI is not enough. That once you have one, you need two. And, once you have two, you need the Vol-im Patch- Work ${ }^{\mathrm{TM}}$ image management system (a software system designed to streamline workflow through all aspects of oncology, including chemotherapy). The issue here is that once a department has started to use the LACI and incorporated it into its treatment protocols, if the LACI machine is not available, through service or machine breakdown, it is more difficult to transfer these patients onto a treatment machine which is not equipped with LACI capabilities. As a result, it becomes necessary to have more than one.

However, CBCT images are stored on the system where the image was acquired and cannot be viewed on another machine, unless a department installs the Vol-im PatchWork system. Therefore, if the patient is scanned on different machines, practitioners are not able to look back through images of the patient without physically moving from one treatment machine 
to the other. At SH, the PatchWork system was installed in 2011. Since its installation it became apparent that using PatchWork to view CBCT images involves further issues. For example, even though the system allows practitioners to assess images from remote workstations (i.e. computer terminals not physically attached to the linear accelerator where the image was acquired), the quality of the images when viewed via Patch- Work is inferior to when viewed through the LACI software. Furthermore, practitioners deem the tools available to perform the image registration processes on PatchWork to be less useful than those on the LACI system. As such, at the SH, images are still only viewed on the LACI system for each linac.

\section{CONCLUSION: CONCEPTUALISING DECADENT TECHNOLOGY}

The large-scale investment in technologies by public hospital organisations, which take place with limited evidence for their effectiveness, provides an illuminating site of study for the critical exploration of technological change. Through the LACI case study, I have brought together the concepts of Baroque Arsenal and path dependence in order to argue that technological systems can become locked-in to specific pathways as the result of representations of expected improvements to treatment.

The Baroque Arsenal, Kaldor (1981) argues, stems from the proposition that modern military technology is not 'advanced', but rather it is 'decadent', invoking characteristics similar to Baroque art or architecture. Furthermore, through the exploration of military technologies, Kaldor argued that Baroque technologies create demands for change. In connecting these arguments to those of path dependence and the case of the LACI, I have unpicked the 'technical interrelatedness' of technological changes. Advancing path dependence to demonstrate how introducing a closely related technology does not only become a low-risk course of action, rather it is demanded (but not determined). Alternatives are obscured and any future changes are utterly dependent upon past introductions.

While strategic planning organisations within the field of radiotherapy, such as the ACORRN, report a consensus of opinion that trials of these sorts of system are unnecessary because the change was 'evidently worth implementing' (Price and Heap, 2008), this position was criticised by others in the field of medical physics; for example, Baumann et al. (2008) argue that enthusiasm should not form the sole basis for IGRT introduction into routine clinical practice.

I have sought to show how this enthusiasm-generated lock-in reflects a decadent technological system. Despite uncertainty, LACI was still introduced. It can be characterised by several distinct features reflecting decadent technology, including: first, decadent technologies are not necessarily an improvement on existing systems. In the LACI case study, this is shown through discussions of how the system's use on patients complicated rather than advanced practice with little practical difference in the quality or accuracy of treatment being delivered. Furthermore, despite the proposed benefits, the LACI system did 
not meet expectations; second, decadent technologies are characterised by ongoing additions forming part of the technological system itself. For example, it is necessary to introduce additional systems, such as the Vol-Im Patchwork system, in order for the LACI to function; and finally decadent technologies are overly complex and generate more information than can be used by other (human and non- human) components of the system. As a result, decadent systems are more elaborate than practice can handle, all the while cementing future pathways.

By presenting the evolution of the LACI system in this paper, it is possible to provide a more wide-ranging picture of how technological objects come to be and to explore the relationship between improvement and innovation. A potential consideration here is whether potential risks to patients are normalised by practitioners and organisations as they strive towards developing techniques that fit their existing practices and technologies.

\section{NOTES}

${ }^{1}$ All names of people and organisations have been changed throughout the paper. LACI is a pseudonymised name.

${ }^{2}$ There is a constant confusion of terms used when referring to this technology. LACI is the original name given to the technology but the commercial name is Pozo. In practice however, practitioners refer to the LACI rather than 'the Pozo'.

${ }^{3}$ This difference in dose is supported in the literature concerning these two image guidance systems (Heyer et al., 2010; Song et al., 2008). 


\section{REFERENCES}

Amols, H. I., Jaffray, D. A. and Orton, C. G. (2006) Point/counterpoint: Image-guided radiotherapy is being overvalued as a clinical tool in radiation oncology, Medical Physics, 33 , pp. $3583-3586$.

Antonuk, L. E. (2002) Electronic portal imaging devices: A review and historical perspective of con- temporary technologies and research, Physics in Medicine and Biology, 47, pp. R31R65. Armstrong, D. (1995) The rise of surveillance medicine, Sociology of Health and Illness, 17(3), pp. 393 - 404. Arthur, W. B. (1990) Positive feedbacks in the economy, Scientific American, 262(2), pp. 92-99.

Ashmore, L. A. (2012) Cakes for Cure: The role of charities in the embedding of innovative cancer treatment technologies, Health Expectations, 15, pp. 401-409.

Barry, A. (2000) Invention and inertia, Cambridge Anthropology, 21, pp. 62-70. Baumann, M., Holscher, T. and Zips, D. (2008) The future of IGRT-Cost benefit analysis, Acta Oncologica, 47, pp. 1188-1192.

Brenner, D. J. and Hall, E. (2007) Computed tomography-An increasing source of radiation exposure, The New England Journal of Medicine, 357, pp. 2277-2284.

Burri, R. V. (2008) Doing distinctions: Boundary work and symbolic capital in radiology, Social Studies of Science, 38(35), pp. 35-62.

Centre for Evidence-Based Purchasing (CEP). (2010a) Technical Evaluation of X-ray Tomographic Image-Guided Radiotherapy Devices: Protocol (London: Crown Publishing).

Centre for Evidence-Based Purchasing (CEP). (2010b) X-ray Tomographic Image-Guided Radio- therapy Systems: Market Review (London: Crown Publishing). Centre for EvidenceBased Purchasing (CEP). (2010c) X-ray Tomographic Image Guided Radio- therapy Systems: Evaluation Report (London: Crown Publishing).

David, P. A. (1985) Clio and the economics of QWERTY, The American Economic Review, 75(2), pp. 332-337.

David, P. A. (2007) Path dependence: A foundational concept for historical social science, Cliometrica, 1, pp. 91-114.

Dosi, G. (1982) Technological paradigms and technological trajectories, Research Policy, 11, pp. $147-162$.

Dosi, G. (1997) Opportunities, incentives and the collective patterns of technological change, The Economic Journal, 107, pp. 1530-1547.

Duck, F. A. (2005) Ultrasound exposure measurement: A hidden science? British Journal of Radiology, 78, pp. 289-291. 
Garud, R., Kumaraswamy, A. and Karnoe, P. (2010) Path dependence or path creation? Journal of Management Studies, 47, pp. 760-774.

Gross, M. (2010) Ignorance and Surprise: Science, Society and Ecological Design (Cambridge, MA: MIT Press).

Haraway, D. (1988) Situated knowledges: The science question in Feminism and the privilege of the partial perspective, Feminist Studies, 14, pp. 575-599.

Heyer, D. E., Serago, C. F., Kim, S., Li, J. G. and Hintenlang, D. E. (2010) An organ and effective dose study of XVI and OBI cone-beam CT systems, Journal of Applied Clinical Medical Physics, 11(2), pp. 181-197.

Hughes, T. P. (1987) The evolution of large scale technological systems, in: W. E. Bijker, T. P. Hughes and T. J. Pinch (Eds) The Social Construction of Technological Systems, pp. 51-82 (Cambridge, MA: MIT Press).

Institute for Cancer Research (ICR). (2010) Conventional or Hypofractionated High Dose Intensity Modulated Radiotherapy for Prostate Cancer: Protocol Version 9.1 (London: ICR).

Jaffray, D. A. (2007) Image-guided radiation therapy: From concept to practice, Seminars in Radiation Oncology, 17, pp. 243-244.

Joyce, K. A. (2008) Magnetic Appeal: MRI and the Myth of Transparency (London: Cornell University Press).

Kaldor, M. (1981) The Baroque Arsenal (New York: Hill and Wang). Kay, A. (2005) A critique of the use of path dependency in policy studies, Public Administration, 83, pp. 553571.

Khoo, V. S. and Dearnaley, D. (2008) The testing of prostate IGRT in clinical trials, in: R. K. Valicenti, A. P. Dicker and D. A. Jaffray (Eds) Image-Guided Radiation Therapy of Prostate Cancer, pp. 233-248 (New York: Informa Healthcare).

Kidder, T. (1982) The Soul of A New Machine (New York: Avon).

Knight, N. (1986) "The new light": X-rays and medical futurism, in: J. J. Corn (Ed) Imagining Tomorrow, pp. 10-34 (London: MIT Press).

Ling, C. C., Yorke, E. and Fuks, Z. (2006) From IMRT to IGRT: Frontierland or Neverland? Radio- therapy and Oncology, 78, pp. 119-122.

Mackenzie, D. and Wajcman, J. (1999) Introductory essay and general issues, in: D. Mackenzie and J. Wajcman (Eds) The Social Shaping of Technology, 2nd ed., pp. 3-27 (Buckingham: Open University Press).

Mcnair, H. A., Hansen, V. N., Parker, C. C., Evans, P. M., Norman, A., Miles, E., Harris, E. J., DelAcroix, L., Smith, E., Keane, R., Khoo, V. S., Thompson, A. C. and Dearnaley, D. P. (2008) A 
comparison of the use of bony anatomy and internal markers for offline verification and an evaluation of the potential benefit of online and offline verification protocols for prostate radio- therapy, International Journal of Radiation Oncology, Biology and Physics, 71, pp. 4150.

Moore, C. J., Amer, A., Marchant, T., Sykes, J. R., Davies, J., Stratford, J., Mccarthy, C., Macbain, C., Henry, A., Price, P. and Williams, P. C. (2006) Developments in and experience of kilovoltage X-ray cone beam image-guided radiotherapy, The British Journal of Radiology, 79, pp. S66 - S78.

Mort, M. (2002) Building The Trident Network (Cambridge, MA: The MIT Press).

Murakami Wood, D. (2009) A new 'baroque arsenal'? Surveillance in a global recession, Surveillance \& Society, 6, pp. 1-2.

Murphy, M. J., Balter, J., Balter, S., Nbencomo, J. A., Das, I. J., Jiang, S. B., Ma, C.-M., Olivera, G. H., Rodebaugh, R. F., Ruchala, K. J., Shirato, H. and Yin, F.-F. (2007) The management of imaging dose during image-guided radiotherapy: Report of the AAPM Task Group 75, Medical Physics, 34, pp. 4041-4063.

National Radiotherapy Advisory Group (NRAG). (2007) Radiotherapy: Developing a World Class Service for England (London: Crown Publishing).

Pasveer, B. (1989) Knowledge of shadows: The introduction of X-ray images in medicine, Sociology of Health and Illness, 11(4), pp. 360-381.

Price, P. and Heap, G. (2008) Implementing image-guided radiotherapy in the UK: Plans for a co- cordinated UK research and development strategy, The British Journal of Radiology, 81, pp. $379-382$.

Song, W. Y., Kamath, S., Ozawa, S., Ani, S. A., Chvetsov, A., Bhandare, N., Palta, J. R., Liu, C. and Li, G. (2008) A dose comparison study between XVI and OBI CBCT systems, Medical Physics, 35(2), pp. 480-486.

Stack, M. and Gartland, M. P. (2003) Path creation, path dependency, and alternative therories of the firm, Journal of Economic Issues, 37, pp. 487-494.

Stirling, A. (2009) Direction, distribution and diversity! Pluralising progress in innovation, sustain- ability and development, Innovation, Sustainability, Development: A New Manifesto. (Steps Centre: University of Sussex).

Tiberius, V. (2011) Towards a "planned path emergence" view on future genesis, Journal of Future Studies, 15, pp. 9-24.

Webster, A. (2007) Health, Technology and Society: A Sociological Critique (Basingstoke: Palgrave Macmillan). 
Wood, L. A. (2012) The ray of hope: Hidden work and the pursuit of accuracy, PhD, Lancaster University. 